\title{
EFFECT OF MECHANICAL TREATMENT ON PROPERTIES OF CELLULOSE NANOFIBRILS PRODUCED FROM BLEACHED HARDWOOD AND SOFTWOOD PULPS
}

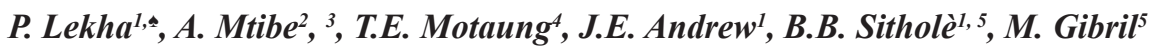

\begin{abstract}
Bleached hardwood and softwood South African kraft pulps were passed through a commercially available micro grinder for varying number of passes and the properties of the resultant pulps were assessed periodically using microscopy, Fourier transform infrared spectroscopy (FTIR), X-ray crystallography (XRD) and Thermogravimetric analysis (TGA). The ultrastructural analysis of the pulp fibres revealed that after 120 passes both hardwood and softwood bleached fibres showed the presence of cellulose nanofibres (CNFs). The FTIR analysis showed no modification to the cellulose structure and side groups upon treatment with the supermasscolloider (SMC). Both hardwood and softwood pulp fibres showed a decline in crystallinity after SMC treatment. For the hardwood pulps there were no major differences between the untreated pulps and those passed through the SMC. In the case of the softwood pulps, the SMC treatment resulted in more thermally stable CNFs compared with the untreated bleached pulps. This was observed at several levels of treatment (40,120 and 200 passes). After 200 passes both the hardwood and softwood kraft pulp fibres produced CNFs with an average width of $11 \mathrm{~nm}$ and lengths with several micrometers.
\end{abstract}

Keywords: Cellulose nanofibrils, Supermasscolloider, South African, TGA, transmission electron microscopy, XRD.

\section{INTRODUCTION}

Cellulose is one of the main constituents of lignocellulosic biomass composed of $\beta$-1,4-linked glucose molecules. Using various mechanical and chemical methods cellulose can be disintegrated into cellulose nanofibrils (CNFs). CNFs supposedly consist of alternating crystalline and amorphous domains and are long, flexible entangled cellulose nanofibres that have lateral dimensions in the order of 10 to $100 \mathrm{~nm}$, and lengths generally in the micrometer scale (Kalia et al. 2014). Recently, interest in CNFs has been increasing because the materials exhibit high specific surface area, high strength and stiffness, low weight and biodegradability (Kalia et al. 2014). Great potential has been shown by several researchers for the use of CNFs in the production of optically transparent composites for flexible electronics, improved barrier membranes, biomedical applications, and as additives in paper and paper board products (Nogi et al. 2005, Paralikar et al. 2008, Clemons et al. 2013, Kalia et al. 2014).

Current research has focused on finding environmentally friendly, high efficiency and low costs methods to isolate CNFs. However, one of the key remaining challenges is translating current laboratory scale technologies to pilot/industrial scale and being able to produce cellulose nanomaterials with consistent properties (Eichhorn 2011).

\footnotetext{
${ }^{1}$ Council for Scientific and Industrial Research (CSIR), Forestry and Forest Products Research Centre, Durban, South Africa. ${ }^{2}$ Council for Scientific and Industrial Research (CSIR), Nonwovens and Composites Research Group, 4 Gomery Avenue, Summerstrand, South Africa.

${ }^{3}$ Department of Textile Science, Faculty of Science, Nelson Mandela Metropolitan University, Port Elizabeth, South Africa.

${ }^{4}$ Department of Chemistry, University of Zululand, KwaDlangezwa, South Africa.

${ }^{5}$ Discipline of Chemical Engineering, University of KwaZulu-Natal, Durban, South Africa.

"Corresponding author: PLekha@csir.co.za
}

Received: 26.10.2015 Accepted: 22.04.2016 
Several mechanical methods can be used to produce CNF viz., homogenization (Turbak et al. 1983, Dufresne et al. 2000, Andresen and Stenius 2007, Jonoobi et al. 2011) microfluidisation (Lee et al. 2009, Ferrer et al. 2012) micro-grinding (Abe et al. 2007, Panthapulakkal and Sain 2012, Wang et al. 2012, Qing et al. 2013); cryocrushing (Chakraborty et al. 2005) and high intensity ultrasonication (Johnson et al. 2009, Qua et al. 2011, Qua et al. 2009, Frone et al. 2011). Each method has its own advantages and disadvantages and is strongly linked to the source material used.

In this study, the use of micro-grinding was chosen for producing CNFs from South African hardwood (Eucalyptus) and softwood (pine) kraft pulps. Micro-grinding was selected over homogenisation and microfluidisation because of the large energy consumption and clogging of the system associated with those techniques (Spence et al. 2011, Khalil et al. 2014). The micro-grinding method involves passing pulp slurries between two grinding stones, one stone remains static and the other rotates (Abe et al. 2007, Wang et al. 2012, Qing et al. 2013). The mechanism of fibrillation in grinding is to break down hydrogen bonds and cell wall structure by shear forces and individualisation of pulp to nanoscale fibres (Siró and Plackett 2010). The grinding disks have bursts and grooves that contact the fibres to disintegrate them into the substructural components (Abe et al. 2007). The material used to manufacture the disks is usually non-porous resins containing silicon carbide. The SMC is an example of a commercial micro-grinding system that mechanically fibrillates cellulosic fibres. Even though micro-grinding has been done on Eucalyptus bleached kraft pulp fibres previously (Wang et al. 2012, Qing et al. 2013), a comparison of hardwood and softwood bleached kraft pulps originating from South Africa has not been studied.

The aim of this study was to assess the effect of the SMC on cellulose properties during the production of CNF using bleached South African hardwood and softwood kraft pulps. Samples were extracted at different number of passes through the SMC to examine the change in cellulose structure, crystallinity, thermal stability and morphology.

\section{EXPERIMENTAL METHODS}

\section{Material}

Fully bleached air-dried Eucalyptus (hardwood) and pine (softwood) kraft pulps obtained from South African commercial sources were used in this study. The pulp sheets were soaked in deionised water overnight prior to processing.

\section{Mechanical nanofibrillation}

A suspension was made of 1 wt.\% kraft pulp samples dispersed in water using a mechanical stirrer at $2000 \mathrm{rpm}$ for $30 \mathrm{~min}$. Afterwards, the suspension was ground using an ultra-fine grinder (Supermasscolloider (SMC), Masuko Sangyo Co., Ltd, Japan) at $2507 \mathrm{rpm}$ in the contact mode to obtain nanofibres. The samples were passed 200 times through the SMC, during which, samples were collected after different number of passes $(0,40,120$ and 200) to investigate any changes in morphological and chemical properties.

\section{Characterisation}

\section{Chemical composition of samples}

The cellulose, hemicellulose and lignin contents of the samples were analysed using standard methods such as TAPPI-T222 om-88 and TAPPI T19m-54. 


\section{Fourier transform infrared spectroscopy (FTIR)}

FTIR of the samples were obtained on a Spectrum 100 FTIR (Perkin Elmer, Waltham, MA, USA) in Attenuated Total Reflection (ATR) mode. The scan of each sample was recorded from 4000 to 400 $\mathrm{cm}^{-1}$ at a resolution of $2 \mathrm{~cm}^{-1}$ in the transmission mode.

\section{X-ray crystallography (XRD) analysis}

The XRD patterns of the bleached softwood and hardwood kraft pulps were measured using a BRUKER AXS (Germany) X-ray Diffractometer D8 Advance equipped with PSD (Position sensitive detector) Vantec-1 detector and $\mathrm{Cu}-\mathrm{K} \alpha$ radiation $(\lambda \mathrm{K} \alpha 1=1,5406 \AA)$. Scattering radiation was detected at $2 \theta=5-90^{\circ}$ at a rate of 1 second per step. The crystallinity indices of the materials analysed were calculated using the peak height method (Segal et al. 1959), crystallinity index (CI) was calculated from the height ratio between the intensity of the crystalline peak $\left(\mathrm{I}_{200}-\mathrm{I}_{\text {non-cr }}\right)$ and total intensity $\left(\mathrm{I}_{200}\right)$ after subtraction of the background signal measured without cellulose according to the following equation:

$$
C I=100 \frac{l_{200}-l_{\text {non }-c r}}{l_{200}}[\%]
$$

where: CI expresses the apparent crystallinity [\%] defined by Segal and co-workers, $I_{200}$ gives the maximum intensity of the peak corresponding to the plane in the sample with the Miller indices 200 at a $2 \theta$ angle of between $22-24^{\circ}$ and $\mathrm{I}_{n o n-c r}$ represents the intensity of diffraction of the non-crystalline material, which is taken at an angle of about $18^{\circ} 2 \theta$ in the valley between the crystalline peaks.

\section{Thermogravimetric analysis (TGA)}

Thermogravimetric analysis was performed using a Perkin Elmer TGA1 from Waltham, Massachusetts, U.S.A. The analyses were done under flowing nitrogen at a constant flow rate of 20 $\mathrm{mL} \mathrm{min}{ }^{-1}$. Samples $(5-10 \mathrm{mg})$ were heated from 25 to $600^{\circ} \mathrm{C}$ at a constant heating rate of $10^{\circ} \mathrm{C} \mathrm{min}{ }^{-1}$.

\section{Optical microscopy (OM)}

A $100 \mu 1$ drop of the dilute suspension was placed on a cleaned glass microscope slide and covered with a glass cover slip. This preparation was then viewed under the Nikon Eclipse i80 compound light microscope. Soft imaging software (SIS) was used to capture images at different magnifications and used for image analysis. Three images were captured for each sample and a total of 15 measurements were performed per image.

\section{Transmission electron microscopy (TEM)}

A $20 \mu \mathrm{l}$ drop of the dilute suspension of a CNF was placed on a formvar-coated grid and allowed to dry under the fume hood. The grids were then stained with a drop of $2 \%$ uranyl acetate solution, for contrast. The stained grids were allowed to dry for $20 \mathrm{~min}$ before being imaged on a JEOL 1010 TEM. Image capture was performed at $100 \mathrm{kV}$ at different magnifications (x20000 to x250000). Three micrographs were captured for each sample and a total of 15 measurements were performed per image. 


\section{RESULTS AND DISCUSSION}

\section{Chemical composition}

The average results of three measurements for cellulose, hemicellulose and lignin are tabulated in Table 1. The softwood bleached pulp showed higher cellulose and lignin contents compared with the hardwood bleached pulp. On the other hand, the bleached hardwood contained higher hemicellulose content. These observations are in line with literature reports which show that softwoods are inherently associated with higher lignin contents while hardwoods are associated with higher percentages of polysaccharides (Betts et al. 1997, Malherbe and Cloete 2002, Kiaei et al. 2014, Mathews et al. 2015). The high hemicellulose content is known for facilitation of disintegration of Eucalyptus pulp into nanofibrils and capable of reducing energy input during mechanical grinding (Iwamoto et al. 2008, Syverud et al. 2011).

Table 1. Percentage chemical compositions of bleached kraft pulp samples.

\begin{tabular}{|c|c|c|c|}
\hline Sample & Cellulose (\%) & Hemicellulose (\%) & Lignin (\%) \\
\hline Bleached hardwood & $67,7 \pm 1,5$ & $27,9 \pm 2,7$ & $4,4 \pm 1,2$ \\
\hline Bleached softwood & $71,2 \pm 2,8$ & $20,3 \pm 5,6$ & $8,5 \pm 2,8$ \\
\hline
\end{tabular}

\section{FTIR}

Figure 1 represents the FTIR spectra of fully bleached hardwood and softwood kraft pulp fibres. FTIR peaks of cellulose are mainly located at $3500-3200 \mathrm{~cm}^{-1}$ (O-H stretching), $3000-2800 \mathrm{~cm}^{-1}(\mathrm{CH}$ stretching), $1476 \mathrm{~cm}^{-1}$ (HCH and HOC bending vibration), 1376 and $1334 \mathrm{~cm}^{-1}$ (HCC, HCO and HOC bending), $1290 \mathrm{~cm}^{-1}$ ( $\mathrm{HCC}$ and $\mathrm{HCO}$ bending) and 1118 and $1095 \mathrm{~cm}^{-1}$ (CC and CO stretching) (Gibril et al. 2014). The fingerprint regions of both hardwood and softwood pulps are similar. The grinding did not affect the chemical structure of cellulose since the functional groups before and after grinding were similar with a negligible shift in wavenumbers, if any (Figure 1). However, it seems as though the peak intensities of the softwood cellulose were slightly higher than those of the hardwoods, particularly at the highest number of passes through the SMC. If that is the case, the observation could likely account for the obtained higher quantity of cellulose in the softwood from the chemical composition analysis.

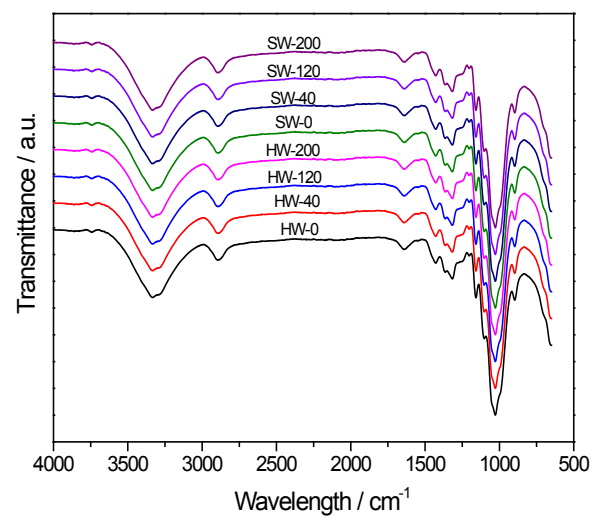

Figure 1. FTIR of bleached hardwood and softwood kraft pulp fibres after 0, 40, 120 and 200 passes through the SMC. 


\section{XRD analysis}

Figure 2 displays XRD patterns of bleached soft and hardwood kraft pulps as well as SMC treated pulps and their respective crystalline index values are shown in Table 2. All the diffractograms of the samples were semi-crystalline displaying an amorphous and crystalline peak. Three peaks of cellulose I were displayed. The peak at $2 \theta=16,4^{\circ}$ was assigned to $[(1-10)$ and (110) $]$ crystallographic planes, $2 \theta=$ $22,7^{\circ}$ assigned to (200) crystallographic plane, and $2 \theta=34,6^{\circ}$ was assigned to (400) crystallographic plane. It is worth noting that the treatment did not significantly alter the crystal structure of the material.

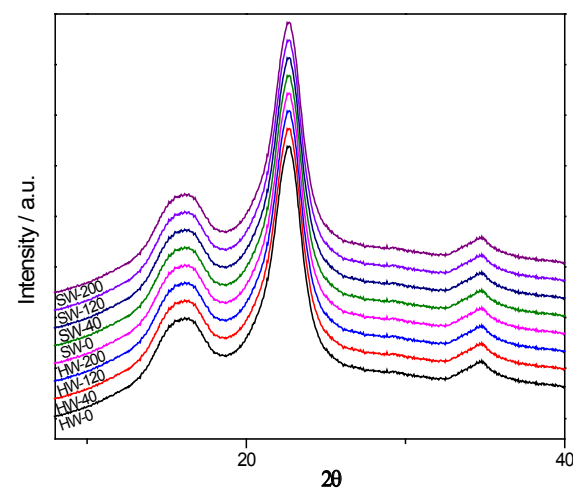

Figure 2. XRD analysis of bleached hardwood and softwood kraft pulp fibers after 0, 40, 120 and 200 passes through the SMC.

Table 2. The average crystallinity indexes of hardwood and softwood kraft pulp (mean \pm standard deviation (SD); number of samples $(\mathrm{n}=3)$.

\begin{tabular}{|c|c|c|c|c|}
\hline Sample & $\begin{array}{c}\text { 0 passes } \\
(\mathbf{\%})\end{array}$ & $\begin{array}{c}\mathbf{4 0} \text { passes } \\
(\mathbf{\%})\end{array}$ & $\mathbf{1 2 0}$ passes $(\mathbf{\%})$ & $\begin{array}{c}\mathbf{2 0 0} \text { passes } \\
(\mathbf{\%})\end{array}$ \\
\hline Hardwood kraft pulp & $63,3 \pm 2,56$ & $56,3 \pm 1,99$ & $57,5 \pm 1,13$ & $60,3 \pm 2,07$ \\
\hline Softwood kraft pulp & $65,9 \pm 2,08$ & $52,2 \pm 1,61$ & $55,3 \pm 1,52$ & $57 \pm 1,73$ \\
\hline
\end{tabular}

However, the crystallinity of both hardwood and softwood pulps decreased after SMC treatment. In fact, generally both hardwood and softwood untreated pulps had higher crystallinity values in comparison to SMC treated pulps. The results show that there was negligible percentage difference of crystallinity index values after the various passes of hardwood and softwood pulp. The observations could be due to the fact that SMC randomly broke apart both crystalline and amorphous regions. Similar findings have been reported by others (Qing et al. 2013, Yousefi et al. 2013, Mtibe et al. 2015). The breakage of the crystalline region is believed to play a part in the defibrillation of nanofibres and cellulose bundles (Qing et al. 2013).

\section{TGA}

Thermogravimetric analysis and differential thermograms (DTG) curves of 0, 40, 120 and 200 passes of bleached hard and softwood kraft pulp fibres through the SMC are shown in Figure 3 (ad). Both bleached hardwood and softwood pulps as well as SMC treated samples showed a single degradation step. Another common observation is a decrease in thermal stability at the minimal passes within the limits of the experiment. It is clear that there is a slight increase in thermal stability of hardwood proportional to the number of passes; however, the 200 passes indicated a slight drop compared with 120 passes (Figure 3a and Figure 3b). A similar pattern was observed for the softwood pulps. However, 200 passes in the latter case decreased significantly in thermal stability to about $5^{\circ} \mathrm{C}$ 
lower than the untreated pulp.
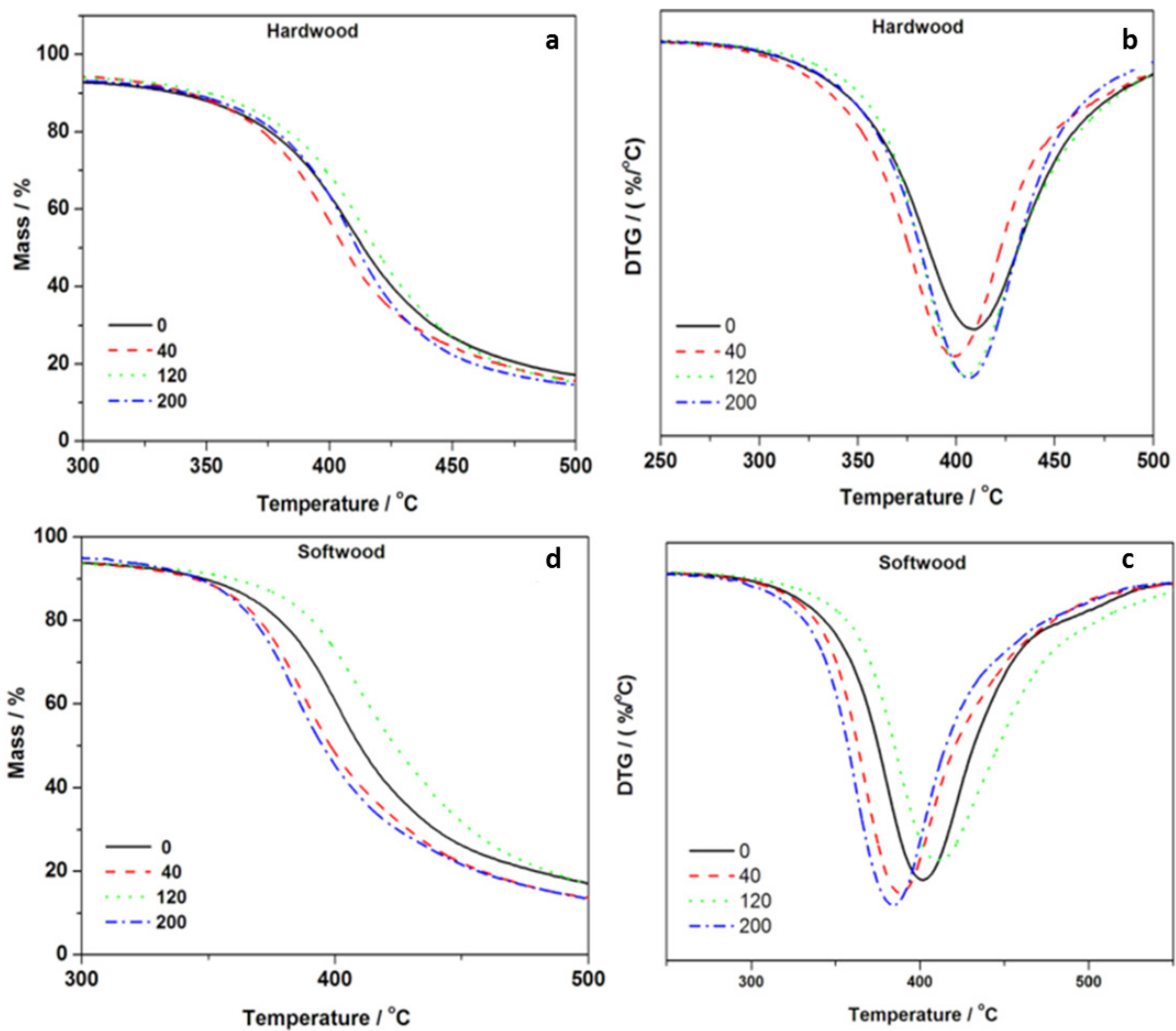

Figure 3. TGA curves and their respective derivative curve (a, b) Hardwood; and (c, d) Softwood.

A decrease in thermal stability of a natural fibre by SMC treatment is well known in literature and typically is related to the degradation of cellulose resulting from friction of two rotating stone disks (Qing et al. 2013, Yousefi et al. 2013, Mtibe et al. 2015). What is more interesting about our results is a decrease in thermal stability at lower pass (120) which is followed by a decrease after more passes (200). Taking into account a catalytic behaviour of lignin and hemicellulose as it is noted in the literature (Qing et al. 2013, Yousefi et al. 2013, Mtibe et al. 2015), it seems as though at 40 passes the SMC mainly reorientated chemical components which favoured catalytic behaviour. The reorientation of the chemical components and/or a high possibility of lignin and hemicellulose degradation during the passing process are likely responsible for the increased thermal stability at 120 passes. However, 200 passes appeared to have resulted into degradation of cellulose, which obviously ensued in low thermal stability.

\section{Morphology of SMC treated samples}

The untreated fibres analysed by optical microscopy showed that the hardwood fibres measured an average of $16 \mu \mathrm{m}$ in width whereas the softwood fibres measured $30 \mu \mathrm{m}$ before processing (Figure 4 ). A gradual disintegration of the sample was observed as the number of passes through the SMC increased (Figure 5). More fibrillation of the fibres was apparent and the quantity of nanoparticles increased in the suspension. After 120 passes the suspensions analysed by TEM showed that nanofibrils had a 
mean width of approximately $18 \mathrm{~nm}$ for hardwood and $13 \mathrm{~nm}$ for softwood (Figure 5). However, there were still large fibres present that had to be fractionated using centrifugation as suggested by Wang et al. (2012). Wang et al. (2012) used the SMC on a bleached Eucalyptus pulp originating from Brazil. Those authors fed the pulp fibre suspension $(1,5 \% \mathrm{w} / \mathrm{w}$ consistency) into the disk grinder continuously by gravity using a loop consisting of a peristaltic pump and plastic tubing. In that study, even after 11 $\mathrm{h}$ of grinding with the SMC large fibre particles were still present. Two main structures were obtained during their experiments, first highly kinked and untwisted fibrils, and second entangled and twisted nanofibres. They found that extended fibrillation could form nanowhiskers with high crystallinity from the untwisted nanofibres.

In this study, after 200 passes, cellulose nanofibrils from both hard and softwood bleached kraft pulp fibres were obtained with mean dimensions of approximately $11 \mathrm{~nm}$. No difference between hardwood and softwood was observed after 200 passes. One of the main advantages of using microgrinding systems is that the mechanical fibre shortening pretreatment necessary for homogenisation and microfluidisation may not be required (Spence et al. 2011).

Recently, Tonoli et al. (2012) showed that Eucalyptus hardwood pulp undergoes easier disintegration and may require less energy as opposed to softwood during grinding because hardwoods have shorter fibres and higher hemicellulose contents. According to Iwamoto et al. (2008) and Syverud et al. (2011), high contents of hemicelluloses can facilitate the release of nanofibrils during the mechanical treatment of the pulp. Therefore these advantages indicate a favourable situation for producing nanofibrils using Eucalyptus pulp fibres as raw material. However, in this study, both hardwood and softwood bleached kraft pulps resulted in approximately similar dimensions of CNFs after 200 passes through the SMC. In fact, an easier disintegration of softwood was observed compared with the hardwood after 120 passes.

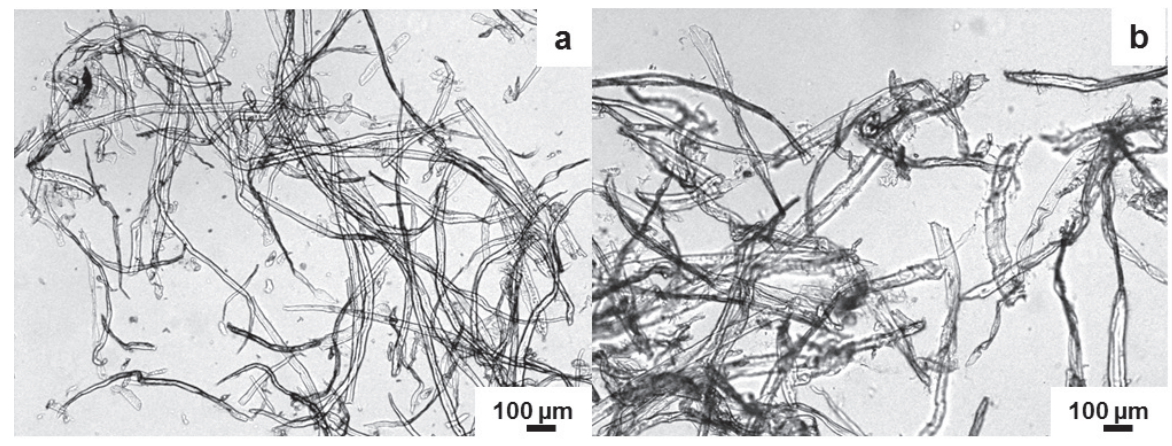

Figure 4. Optical microscopy analysis of South African bleached kraft pulp fibres prior to SMC treatment (a) Hardwood and (b) Softwood.

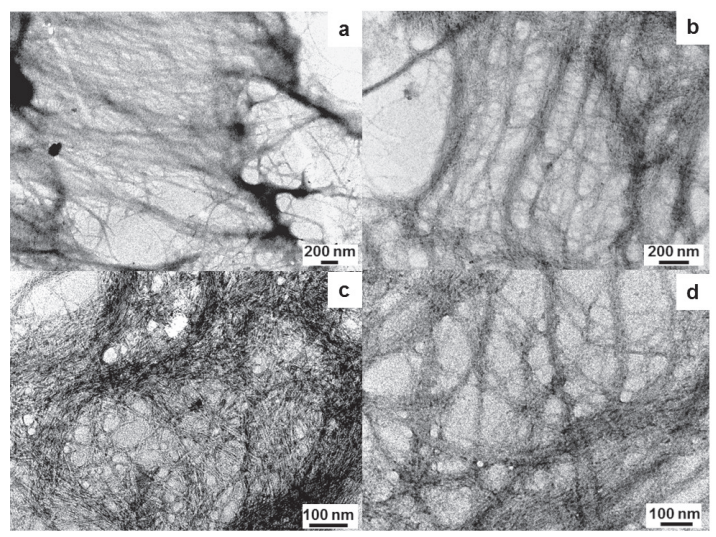

Figure 5. TEM images of bleach kraft fibres through the SMC; (a) 120 passes hardwood; (b) 120 passes softwood; (c) 200 passes hardwood; and (d) 200 passes softwood. 


\section{CONCLUSIONS}

Bleached soft and hardwood pulp as well as SMC treated pulp were characterised by TAPPI standard methods, FTIR, XRD, TGA and TEM. FTIR showed negligible differences between SMC treated and untreated pulps. XRD analysis showed that the crystallinity of the samples decreased after SMC treatment. TGA showed that the SMC treated pulps did not follow the very same degradation mechanisms. Untreated hardwood pulp was more thermally stable as compared with treated hardwood pulp. In the case of softwood pulp, 120 passes was more thermally stable in comparison to untreated softwood pulp and 40 and 200 passes treated pulps. The difference between the soft and hardwood disintegration mechanisms could be due to the difference in cellulose content of pure pulps that could be explained in relation to their botanical classification, which also possibly led to different reactions to treatments. After SMC treatment bleached hardwood and softwood pulps individual fibres were defibrillated and produced nanofibres with average diameters of $11 \mathrm{~nm}$ and lengths estimated to be in the micro-scale.

\section{ACKNOWLEDGEMENTS}

This work was financially supported by the Young Researcher's Establishment Fund (YREF) awarded from the CSIR. The technical assistance of the staff from the Forestry and Forest Products Research Centre and the Material Science and Manufacturing group is greatly appreciated.

\section{REFERENCES}

Abe, K.; Iwamoto, S.; Yano, H. 2007. Obtaining cellulose nanofibres with a uniform width of 15 $\mathrm{nm}$ from wood. Biomacromolecules 8:3276-3278.

Andresen, M.; Stenius, P. 2007. Water-in-oil emulsions stabilized by hydrophobized microfibrillated cellulose. Journal of Dispersion Science and Technology 28:837-844.

Betts, R.A.; Cox, P.M.; Lee, S.E.; Woodward, F.L. 1997. Contrasting physiological and structural vegetation feedbacks in climate change simulations. Nature 387:796-799.

Chakraborty, A.; Sain, M.; Kortschot, M. 2005. Cellulose microfibrils: a novel method of preparation using high shear refining and cryocrushing. Holzforschung 59:102-107.

Clemons, C.; Sedlmair, J.; Illman, B.; Ibach, R.; Hirschmugl, C. 2013. Chemically imaging the effects of the addition of nanofibrillated cellulose on the distribution of poly (acrylic acid) in poly (vinyl alcohol). Polymer 54:2058-2061.

Dufresne, A.; Dupeyre, D.; Vignon, M.R. 2000. Cellulose microfibrils from potato tuber cells: processing and characterization of starch-cellulose microfibril composites. Journal of Applied Polymer Science 76:2080-2092.

Eichhorn, S.J. 2011. Cellulose nanowhiskers: promising materials for advanced applications. Soft Matter 7:303-315.

Ferrer, A.; Filpponen, I.; Rodríguez, A.; Laine, J.; Rojas, O.J. 2012. Valorization of residual Empty Palm Fruit Bunch Fibres (EPFBF) by microfluidization: production of nanofibrillated cellulose and EPFBF nanopaper. Bioresource Technology 125:249-255. 
Frone, A.N.; Panaitescu, D.M.; Donescu, D. 2011. Some aspects concerning the isolation of cellulose micro-and nano-fibres. UPB Buletin Stiintific, Series B: Chemistry and Materials Science $73: 133-152$.

Gibril, M.E.; Li, X.D.; Zhang, Y.; Han, K.Q.; Yu, M.H. 2014. Green Process for Preparing Cellulose/Reactive Epoxy (BGE) through an In Situ Chemical Blend (Pre-Hybrid Polymer BioComposite). Advanced Materials Research 842:39-42.

Iwamoto, S.; Abe, K.; Yano, H. 2008. The effect of hemicelluloses on wood pulp nanofibrillation and nanofibre network characteristics. Biomacromolecules 9:1022-1026.

Johnson, R.K.; Zink-Sharp, A.; Renneckar, S.H.; Glasser, W.G. 2009. A new bio-based nanocomposite: fibrillated TEMPO-oxidized celluloses in hydroxypropylcellulose matrix. Cellulose $16: 227-238$.

Jonoobi, M.; Harun, J.; Tahir, P.M.; Shakeri, A.; Saifulazry, S.; Makinejad, M.D. 2011. Physicochemical characterization of pulp and nanofibres from kenaf stem. Materials Letters 65:10981100 .

Kalia, S.; Boufi, S.; Celli, A.; Kango, S. 2014. Nanofibrillated cellulose: surface modification and potential applications. Colloid and Polymer Science 292:5-31.

Khalil, H.P.S.A.; Davoudpour, Y.; Islam, M.N.; Mustapha, A.; Sudesh, K.; Dungani, R.; Jawaid, M. 2014. Production and modification of nanofibrillated cellulose using various mechanical processes: a review. Carbohydrate Polymers 99:649-665.

Kiaei, M.; Tajik, M.; Vaysi, R. 2014. Chemical and biometrical properties of plum wood and its application in pulp and paper production. Maderas-Cienc Tecnol 16(3):313-322.

Lee, S.Y.; Chun, S.J.; Kang, I.A.; Park, J.Y. 2009. Preparation of cellulose nanofibrils by highpressure homogenizer and cellulose-based composite films. Journal of Industrial and Engineering Chemistry 15:50-55.

Malherbe, S.; Cloete, T.E. 2002. Lignocellulose biodegradation: fundamentals and applications. Reviews in Environmental Science and Biotechnology 1:105-114.

Mathews, S.L.; Pawlak, J.; Grunden, A.M. 2015. Bacterial biodegradation and bioconversion of industrial lignocellulosic streams. Applied Microbiology and Biotechnology 99:2939-2954.

Mtibe, A.; Linganiso, L.Z.; Mathew, A.P.; Oksman, K.; John, M.J.; Anandjiwala, R.D. 2015. A comparative study on properties of micro and nanopapers produced from cellulose and cellulose nanofibres. Carbohydrate Polymers 118:1-8.

Nogi, M.; Handa, K.; Nakagaito, A.N.; Yano, H. 2005. Optically transparent bionanofibre composites with low sensitivity to refractive index of the polymer matrix. Applied Physics Letters $87(24)$.

Panthapulakkal, S.; Sain, M. 2012. Preparation and characterization of cellulose nanofibril films from wood fibre and their thermoplastic polycarbonate composites. International Journal of Polymer Science: doi:10.1155/2012/381342.

Paralikar, S.A.; Simonsen, J.; Lombardi, J. 2008. Poly (vinyl alcohol)/cellulose nanocrystal barrier membranes. Journal of Membrane Science 320:248-258.

Qing, Y.; Sabo, R.; Zhu, J.; Agarwal, U.; Cai, Z.; Wu, Y. 2013. A comparative study of cellulose nanofibrils disintegrated via multiple processing approaches. Carbohydrate Polymers 97:226-234. 
Qua, E.; Hornsby, P.; Sharma, H.; Lyons, G. 2011. Preparation and characterisation of cellulose nanofibres. Journal of Materials Science 46:6029-6045.

Qua, E.; Hornsby, P.; Sharma, H.; Lyons, G.; Mccall, R. 2009. Preparation and characterization of poly (vinyl alcohol) nanocomposites made from cellulose nanofibres. Journal of Applied Polymer Science 113:2238-2247.

Segal, L.; Creely, J.; Martin, A.; Conrad, C. 1959. An empirical method for estimating the degree of crystallinity of native cellulose using the X-ray diffractometer. Textile Research Journal 29:786-79.

Siró, I.; Plackett, D. 2010. Microfibrillated cellulose and new nanocomposite materials: a review. Cellulose 17:459-494.

Spence, K.L.; Venditti, R.A.; Rojas, O.J.; Habibi, Y.; Pawlak, J.J. 2011. A comparative study of energy consumption and physical properties of microfibrillated cellulose produced by different processing methods. Cellulose 18:1097-1111.

Syverud, K.; Xhanari, K.; Chinga-Carrasco, G.; Yu, Y.; Stenius, P. 2011. Films made of cellulose nanofibrils: surface modification by adsorption of a cationic surfactant and characterization by computer-assisted electron microscopy. Journal of Nanoparticle Research 13:773-782.

Tonoli, G.; Teixeira, E.; Corrêa, A.; Marconcini, J.; Caixeta, L.; Pereira-da-Silva, M.; Mattoso, L. 2012. Cellulose micro/nanofibres from Eucalyptus kraft pulp: preparation and properties. Carbohydrate Polymers 89:80-88.

Turbak, A.F.; Snyder, F.W.; Sandberg, K.R. 1983. Microfibrillated cellulose. US Patent No 4,374,702A. 22 Feb. 1983

Wang, Q.; Zhu, J.; Gleisner, R.; Kuster, T.; Baxa, U.; Mcneil, S. 2012. Morphological development of cellulose fibrils of a bleached Eucalyptus pulp by mechanical fibrillation. Cellulose 19:1631-1643.

Yousefi, H.; Faezipour, M.; Hedjazi, S.; Mousavi, M.M.; Azusa, Y.; Heidari, A.H. 2013. Comparative study of paper and nanopaper properties prepared from bacterial cellulose nanofibres and fibres/ground cellulose nanofibres of canola straw. Industrial Crops and Products 43:732-737. 